\title{
Papillary Ductal Breast Hyperplasia
}

National Cancer Institute

\section{Source}

National Cancer Institute. Papillary Ductal Breast Hyperplasia. NCI Thesaurus. Code C5200.

Benign papillary proliferation within the ductal system of the breast parenchyma. 